\title{
Consideration of risk management practices in regulatory risk assessments: evaluation of field trials with micro-dams to reduce pesticide transport via surface runoff and soil erosion
}

\author{
Stephan Sittig ${ }^{1 *} \mathbb{D}$, Robin Sur ${ }^{2}$, Dirk Baets ${ }^{3}$ and Klaus Hammel ${ }^{2}$
}

\begin{abstract}
Background: On sloped agricultural fields, water and sediment can be transported downhill as runoff and erosion. This process can cause losses of valuable top soil material, water resources for plant availability, and nutrients as well as transport of plant protection products (PPP) into adjacent surface water bodies. In the European and the US risk assessment for the registration of PPP, runoff and erosion are numerically calculated with the simulation model PRZM which uses the USDA runoff curve number (CN) concept for the water movement. Results from runoff field trials were used to estimate the effect of dedicated management practices in terms of mitigating runoff and erosion, i.e. creating micro-dams between the ridges of potato fields or in maize cultivation on model input parameters.

Results: Application of different cultivation and tillage techniques (micro-dams/bunds) showed a consistent decrease of the measured quantities of runoff, erosion, and PPP transport as well as of the calculated CN and predicted environmental concentrations in surface water. The results presented here support the approach to quantitatively consider in-field risk mitigation measures (if applied) in the context of regulatory surface water exposure calculations, as proposed by the SETAC MAgPIE workshop.
\end{abstract}

Conclusion: Based on these data, a robust case can be made to consider innovative runoff mitigation for risk assessment purposes by, e.g. lowering the $\mathrm{CN}$ in the exposure scenarios. In the assessment presented herein, an average decrease in the mean of the derived CN of 86 of 21 points ( \pm 11 , 10th percentile: 12) for potatoes could be derived. For maize, the mean calculated $\mathrm{CN}$ of 73 was lowered on average by 3 points.

Keywords: Pesticides, Mitigation, Runoff, Soil erosion, Micro-dams, Risk assessment, Predicted environmental concentrations

\section{Background}

On sloped agricultural fields, water and sediment can be transported downhill as runoff and erosion. These processes cause loss of valuable soil, nutrients and

\footnotetext{
*Correspondence: sittig.stephan@t-online.de

${ }^{1}$ knoell Germany GmbH, Konrad-Zuse-Ring 25, 68163 Mannheim,

Germany

Full list of author information is available at the end of the article
}

plant protection products (PPP) into adjacent surface water bodies. The erosion of soil material from agricultural fields has several short-term and long-term consequences: from the removal of seeds and a covering of the emerging plants to the loss of fertility and organic substance. Pesticides are generally transported in solution via runoff or sorbed to soil particles via erosive transport. The relation between both transportation pathways depends amongst others on the physio-chemical 
and environmental properties of the individual substance under investigation [33].

In the European and US risk assessment framework, surface runoff is one building block for the estimation of potential risks for the aquatic environment, i.e. for surface water bodies adjacent to agricultural fields. In Europe and the US, runoff of PPP is calculated with the Pesticide Root Zone Model [36], which uses the USDA runoff curve number $(\mathrm{CN})$ concept [43] to quantify the amount of runoff water. In this concept, assuming a high $\mathrm{CN}$ indicates a relatively large runoff susceptibility of a field compared to a lower CN. Hawkins [23] has demonstrated the importance of an accurate determination of the $\mathrm{CN}$, preferably via direct measurements of runoff following precipitation. The European registration procedure is based on Regulation (EC) No 1107/2009. A corresponding modelling framework for environmental fate was established by the FOrum for Co-ordination of pesticide fate models and their Use $[18,19]$. To calculate predicted environmental concentrations for different surface water bodies (PECsw), predefined standard scenarios (for runoff, drainage and drift) are applied. These are based on European conditions in different geographical regions assuming certain percentiles of representativeness. To derive PECsw following from runoff, the output of daily runoff fluxes, erosion masses and pesticide mass outputs from agricultural fields given by PRZM simulations is applied as input for the surface water model FOCUS TOXSWA [5]. With the latter, concentration dynamics in surface water and corresponding sediment are calculated for model water bodies representing streams, ditches and ponds. The procedure to derive PECsw is currently under revision to take a 20-year simulation period into account with the aim of more robust calculations of PECsw [14]. In the US, the legal basis for pesticide regulation is the Federal Insecticide, Fungicide and Rodenticide Act [42] and the Endangered Species Act [17]. Runoff/erosion and drift are the only entry routes for regulatory exposure assessments. The corresponding aquatic exposure endpoints are EEC (estimated environmental concentration for ecological risk assessments) and EDWC (estimated drinking water concentration for dietary risk assessments). These values are calculated within the PWC shell (pesticide in water calculator) with PRZM coupled with the variable volume water model (VVWM) with a pond as the receiving water body [16].

Due to the planting in rows and the resulting bare soil in between (together with low plant density), it is reasonable to assume that the cultivation of row crops such as potatoes or maize leads to a higher vulnerability to surface runoff compared to wheat or root crop [2]. The German Environmental Protection Agency recommends the "earthing up of transverse ridges for potato crops" to prevent soil erosion [40]. Generally, several mitigation strategies can be applied to reduce the amount of superficial runoff [35]: vegetated buffer/filter strips, grassed depressions, waterways, ditches or wetland. Furthermore, measures of Good Agricultural Practice can be applied, e.g. conservation tillage [38] or the usage of specific machinery to improve infiltration. All these practices aim to reduce the runoff velocity, increase the capability of the soil to retain water on the surface and subsequently to facilitate infiltration.

The technique to construct micro-dams between the ridges of ridge-furrow tillage systems is a largely known agricultural technique [22, 26, 37, 39]. Other terms than micro-dams are furrow-diking, tied ridges, furrow damming, basin tillage, basin listing, microbasin tillage, diked furrows, basin tillage [26, 37]. Corresponding devices are commercially available, e.g. the Barbutte from Cottard (France), the Dycker from Grimme (Germany), or the partition inserting machine from Netagco-Rumpstad/ AgriMaas (The Netherlands). Distinct strategies in terms of tillage and plough management to preserve the fields and increase infiltration are also applied in maize cultivation, e.g. disc or drum ploughs to create small dams or holes between the rows.

Elhakeem and Papanicolaou [15] and Oliveira et al. [28] presented general procedures to derive $\mathrm{CN}$ from field trials. Hence, such data can be used to assess the effect of micro-dams or other management practices between the ridges of potato or maize fields and to quantify the mitigation effect by deriving the $\mathrm{CN}$ reduction. The SETAC MAgPIE workshop [35] proposed a lowering of the CN by 3 points after the application of in-field bunds in row crops.

The objective of the present work is to enlarge the small database for the effects in reducing runoff, soil erosion and PPP transport following the application of certain mitigation measures in potato (i.e. micro-dams) and in maize (similar tillage techniques) cultivation. To this end, runoff $\mathrm{CN}$ were calculated based on rainfall-runoff relations reported in field studies. Furthermore, reductions in soil erosion and in pesticide loadings in these field studies were derived quantitatively. The herein calculated $\mathrm{CN}$ reductions can be used in environmental risk assessment to quantify the effects of the optional mitigation measures in terms of runoff. A potential representation in the concept of calculation of predicted environmental concentrations for surface water (PECsw) is presented as well.

\section{Methods}

Trials under consideration in this study

In this paper, seven studies (newly designed and from literature) were evaluated-Table 1 lists the experimental 
Table 1 Details of the studies under investigation; n.a.: not available; n.ap.: not applicable

\begin{tabular}{|c|c|c|c|c|c|c|c|c|}
\hline & \multicolumn{6}{|l|}{ Potatoes } & \multicolumn{2}{|l|}{ Maize } \\
\hline & \multicolumn{2}{|c|}{ Olivier et al. [29] } & $\begin{array}{l}\text { Goffart et al. } \\
{[21]^{\mathrm{a}}}\end{array}$ & \multirow[t]{2}{*}{$\begin{array}{l}\text { Aurbacher } \\
\text { et al. [6] }\end{array}$} & \multirow[t]{2}{*}{ Areas [3] } & \multirow[t]{2}{*}{ Areas [4] } & \multirow[t]{2}{*}{ CIPF [7] } & \multirow[t]{2}{*}{ UCL [41] } \\
\hline & & & 20092010 & & & & & \\
\hline Device & \multicolumn{2}{|l|}{ Barbutte } & Barbutte & $\begin{array}{l}\text { Self-developed } \\
\text { prototypes }\end{array}$ & \multicolumn{2}{|c|}{ Prototypes (Grimme) } & $\begin{array}{l}\text { Disc and drum } \\
\text { plough }\end{array}$ & $\begin{array}{l}\text { Disc and drum } \\
\text { plough }\end{array}$ \\
\hline Soil type & \multicolumn{2}{|l|}{ Sandy loam } & $\begin{array}{l}\text { Various, up to } \\
28 \% \text { sand }\end{array}$ & $\begin{array}{l}\text { Silty"loess } \\
\text { soils" }\end{array}$ & Silt loam & Loam & Sandy loam & n.a. \\
\hline Irrigation & \multicolumn{2}{|l|}{ No } & No & Yes & Yes & Yes & No & No \\
\hline Micro-dam height $(\mathrm{cm})$ & \multicolumn{2}{|l|}{$10-17$} & \multirow[t]{2}{*}{$10-17$} & $20-27$ & $\approx 5$ & 13 & \multicolumn{2}{|l|}{ Several cm } \\
\hline $\begin{array}{l}\text { Distance between the } \\
\text { micro-dams }(\mathrm{m})\end{array}$ & 1.5 & 1.6 & & $1.5-8$ & 1.6 & 1.5 & Several cm & \\
\hline Plot length/area & $30 \mathrm{~m}$ & $30 \mathrm{~m}$ & & Unknown & $\approx 5 \mathrm{~m}$ & Unknown & $72 \mathrm{~m}^{2}$ & $75 \mathrm{~m}^{2}$ \\
\hline Slope (\%) & $>3$ & $<3$ and $>3$ & & $2-10$ & $<3$ & $<4$ & 9,16 & $10-12$ \\
\hline $\begin{array}{l}\text { Plant protection product(s) } \\
\text { applied? }\end{array}$ & Yes, $n=4$ & Yes, $n=5$ & & No & No & No & Yes, $n=4$ & Yes, $n=1$ \\
\hline
\end{tabular}

The studies of Olivier et al. [29] and CIPF [7] were newly designed and more detailed results were available for evaluation by the authors

a All information given as mean of 5 trials over 2 years, consisting of trials both with slope $<3 \%$ and $>3 \%$

b Mean values over 35 trials reported only

details. Runoff CN were calculated based on the reported measurements of precipitation and runoff (see Chapter 2.2 for the calculation procedure). Reductions in runoff volumes, erosion masses and plant protection product loads were derived quantitatively. In Additional file 1, all experimental results, together with the calculated runoff $\mathrm{CN}$ can be found (Additional file 1: Tables S1-S13).

The five potato studies were conducted either on one site for a complete season [29], reported as annual sums from three sites over 2 years [21], in a research project compiling 35 trials on silty loess soil trials in south-western Germany [6], in a single-event study design using both pre-wetted and dry soil [3], or an irrigation trial, applying $30 \mathrm{~mm}$ of rain [4]. In the first trials, the Barbutte from Cottard (France, see Fig. 1) was applied to construct micro-dams. Similar devices were used in the remaining three trials.

The two maize studies were conducted with the application of two types of micro-dam-creating techniques: disc and drum plough. Observations were reported over a complete season [7] or from two storm events [41], respectively. In Fig. 2, the two devices and the resulting patterns on the agricultural fields are shown.

Generally, in 4 of the 7 studies, plant protection products were applied (cf. Tables S14, S15 in Additional file 1 for information on mobility). In the potato trials

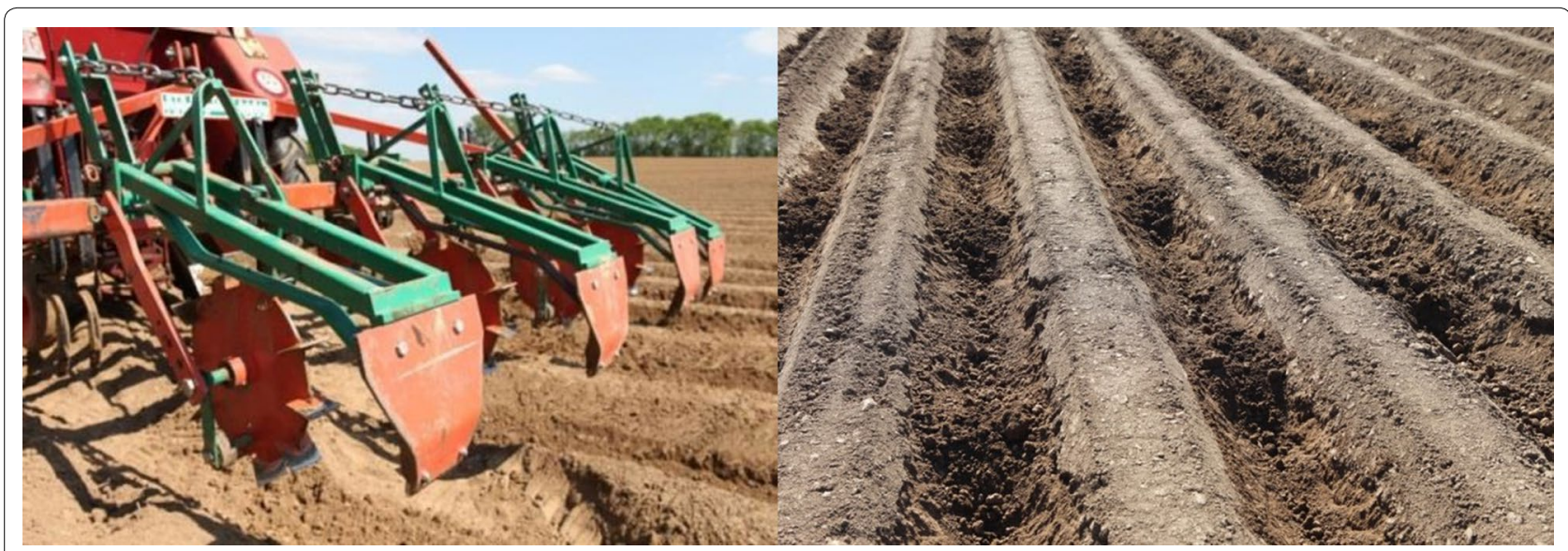

Fig. 1 Cottard Barbutte equipment and in-furrow micro-dams (Fotos: Dirk Baets) 


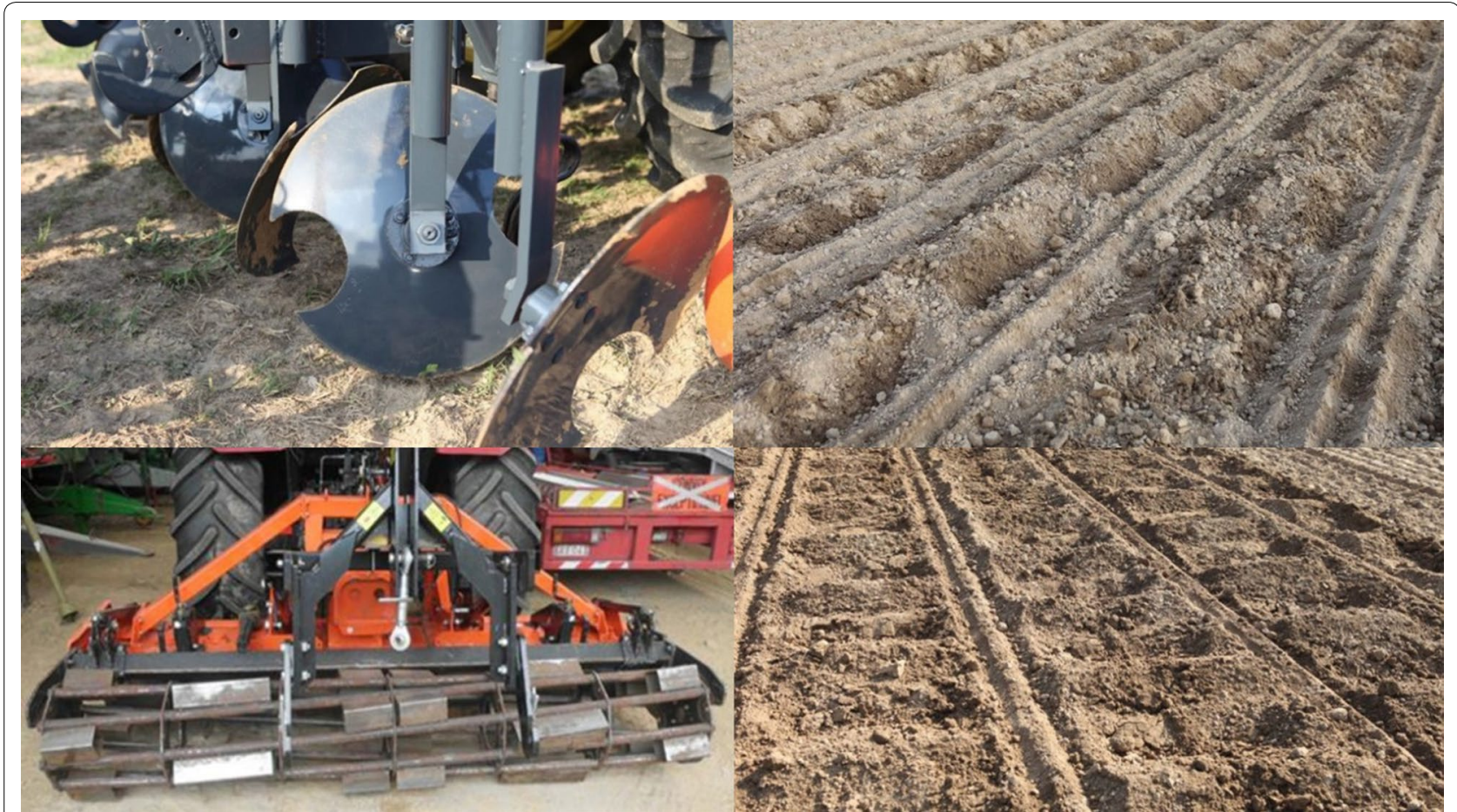

Fig. 2 Devices and resulting structures after usage in the cultivation of maize: upper row, disc plough; lower row, drum plough (Fotos: Dirk Baets)

in Olivier et al. [29], aclonifen [10], linuron [20], flufenacet [30], and metribuzin [9] and in Goffart et al. [21], fluazinam [11], mancozeb [31], aclonifen, flufenacet, and metribuzin were used. In the maize trials, flufenacet, isoxadifen-ethyl [32], tembotrione [13], terbutylazin [12] were applied in the CIPF [7] trial, and flufenacet in the UCL [41] trial.

\section{Concept of the runoff curve number and derivation from the trials}

In the USDA CN approach (as used in the European regulatory context), direct runoff is regarded, i.e. a combination of channel runoff, surface runoff, and subsurface flow [43]. In this study, measured relations between precipitation and runoff were used for the calculation of runoff $\mathrm{CN}$, representing the transformation of total precipitation amounts into total runoff amounts.

In the representation of runoff after Mockus [27], a potential maximum retention $\mathrm{S}(\mathrm{mm})$ after beginning of the runoff is defined. Assuming an initial abstraction (consisting of interception, infiltration during early parts of the storm, and surface depression storage) of $0.2 * S$, runoff $Q[\mathrm{~mm}]$ is calculated based on precipitation $P$ $(\mathrm{mm})$ :

$$
Q=\frac{(P-0.2 * S)^{2}}{P+0.8 * S}
$$

Equation (1) can be solved for S (also called: daily watershed parameter) yielding

$$
S=5\left[P+2 Q-\left(4 Q^{2}+5 P Q\right)^{1 / 2}\right] .
$$

The relation between $\mathrm{S}[\mathrm{mm}]$ and $\mathrm{CN}$ is given as [24]:

$$
S=25.4 \mathrm{~mm} *(1000 / \mathrm{CN}-10),
$$

which can be solved for $\mathrm{CN}$ as:

$$
\mathrm{CN}=\frac{1000}{10+S / 25.4 \mathrm{~mm}} .
$$

For given $P$ and $Q$ we solve Eq. ( 2) for $\mathrm{S}$ and insert the solution into Eq. (4) to finally obtain $\mathrm{CN}$.

The theoretical maximum $\mathrm{CN}$ of 100 leads to $S=0$ and finally to $Q=P$. The $\mathrm{CN}$ is the driving parameter of surface runoff in the risk assessment models. Figure 3 shows the relation between precipitation and runoff for different $\mathrm{CN}$ for the example of one of the trials under investigation, i.e. example results from Areas [3]. 


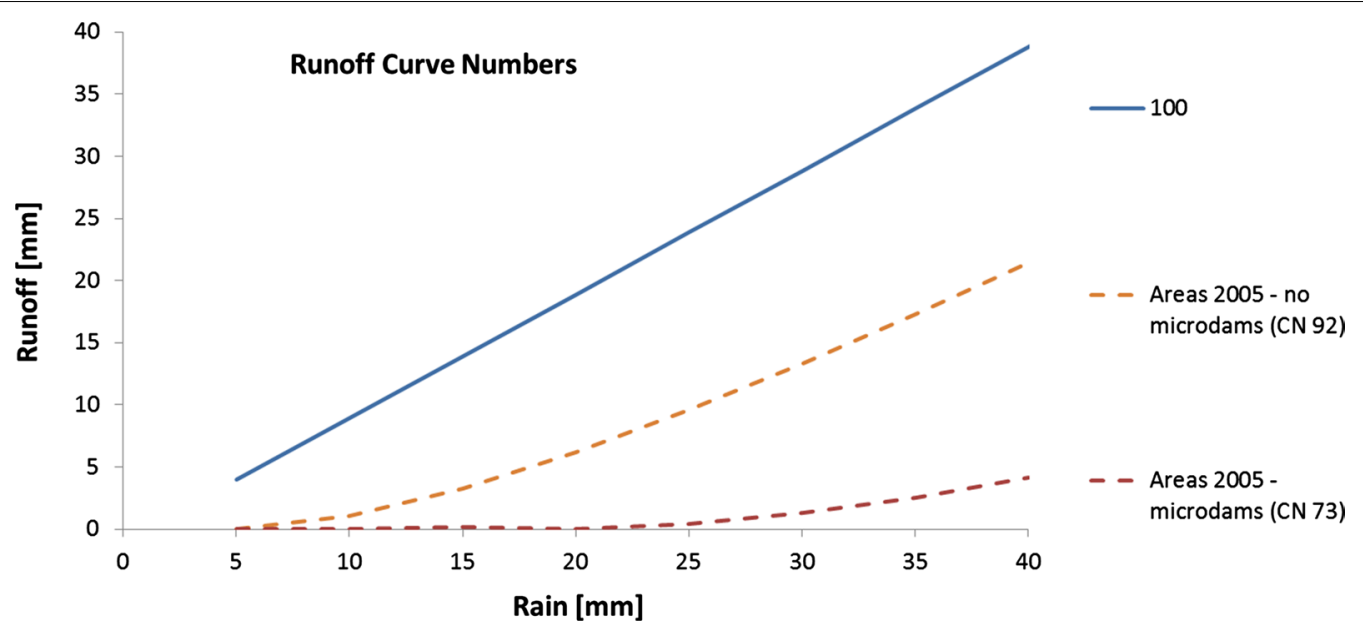

Fig. 3 Relationship between rain and runoff expressed by the runoff curve number (CN). The maximum of 100 describes a 1:1 line; CN 92 and 73 are examples from one of the trials under investigation (Areas, 2005)

\section{The curve number concept used in the regulatory} framework

In the context of risk assessment, $\mathrm{CN}$ are defined scenario-specific and crop-specific, being a function of soil type, soil drainage properties, and management practices. Furthermore, crop stages are taken into account as defined in [19, Appendix D]. For potatoes and maize, the stages of emergence and maturation are defined in scenario $\mathrm{R} 1$ with the average $\mathrm{CN}$ of 82 , being 87 at harvest time, and 91 during fallow. Average $\mathrm{CN}$ refer to intermediate moisture conditions, named antecedent moisture condition (AMC) II.

Curve numbers show variability depending on several boundary conditions, such as the AMC, based on a 5-day precipitation history before each event. This index, denoting AMC II as average conditions, AMC I as dry and AMC III as wet conditions, is calculated by FOCUS PRZM (i.e. PRZM 3.22) on a daily basis. This depends on the AMC in the upper soil layers [44]. The $\mathrm{CN}$ are adjusted using the following rules [36]:

$$
\begin{aligned}
\mathrm{CN}_{\mathrm{AMC} \mathrm{I}} & =\frac{4.2 * \mathrm{CN}_{\mathrm{AMC} \mathrm{II}}}{10-0.058 \mathrm{CN}_{\mathrm{AMC} \mathrm{II}}}, \\
\mathrm{CN}_{\mathrm{AMC} \mathrm{III}} & =\frac{23 * \mathrm{CN}_{\mathrm{AMC} \mathrm{II}}}{10+0.13 \mathrm{CN}_{\mathrm{AMC} \mathrm{II}}} .
\end{aligned}
$$

The actual applied CN in the PRZM model are calculated in a linear interpolation while being restricted in variability and never reaching the endpoints of AMC I or AMC III. For further information please refer to Young and Fry [44].

Here, the aim was to arrive at CNs for AMC II by deriving the mean of all $\mathrm{CN}$ from the unique events
[43]. In the trials considering a complete season of rain-runoff relations (i.e. $[7,29]$ ), the $\mathrm{CN}$ were averaged rainfall-weighted due to the assumption that the reliability of the $\mathrm{CN}$ is proportional to the height of the rainfall event. In general, when averaging over various experimental conditions, and not taking detailed information on the specific moisture conditions into account, the assumption of intermediate moisture conditions was judged to be adequate.

\section{Example higher-tier calculations of maximum predicted environmental concentrations for surface water (PECsw,max)}

To investigate the effects of lowering $\mathrm{CN}$ in the risk assessment, example calculations for FOCUS surface water scenarios were conducted. To this end, all standard values for the $\mathrm{CN}$ for AMC II for the early stage, crop maturation, harvest and fallow were exemplarily lowered by $10 \%$ (and the CN for AMC I and III were calculated by the model, as usually, described above). For the three substances aclonifen, fluazinam and metribuzin, which show a relatively immobile, intermediate and mobile behaviour, respectively (see Additional file 1: Table S16 for basic substance properties) maximum PECsw (PECsw,max) were calculated exemplarily. All other parameters were applied unchanged from the original FOCUS surface water scenarios for potatoes.

The FOCUS surface water scenarios considered here are stream scenarios with a plant protection product treated field of 1 ha adjacent to the water body. This water body is connected to a 100-ha upstream catchment, of which $20 \%$ are treated with plant protection product. This fraction of treated area can be also considered as the aeric fraction of the target crop in the 
catchment. Such a setting would occur for example if four different agricultural crops were grown taking $80 \%$ of the area and $20 \%$ would be non-arable land such as pasture or forest (see [19] for details on the scenario definition). The resulting concentration in the stream is essentially the sum of all mass fluxes (from $20+1$ ha) divided by all water fluxes (from $100+1$ ha) to the water body. The micro-dams are assumed to be installed on the treated area only so that the generation of runoff water and mass fluxes are reduced on 21 ha. On the remaining 80 ha the runoff water entry is unchanged, runoff mass entries are zero. This setup can be described by the formula:

$$
\mathrm{PEC}_{\mathrm{sw}}^{\text {mitigation }}=\mathrm{PEC}_{\mathrm{sw}}^{\mathrm{no} \text { mitigation }} * \frac{1-f}{1-f_{a} * f}
$$

with the runoff reduction factor:

$$
f=\frac{\text { runoff flux }_{\text {no miti }}-\text { runoff flux }_{\text {miti }}}{\text { runoff flux }_{\text {no miti }}}
$$

where $f_{a}=$ fraction area treated $(=21$ ha/101 ha $=0.208$, FOCUS definition for stream scenarios).

If for example the mitigation reduces runoff water and mass fluxes from the treated area by one half $(f=0.5)$, the PECsw is reduced by about a fraction of 0.45 . This procedure is in accordance with the established practice to consider mitigation of runoff entries in European environmental risk assessment [25], e.g. using the software SWAN [8].

The runoff reduction factor $f$ was calculated using the runoff mass fluxes as evaluated by PRZM (and used as input for TOXSWA) on the day of the corresponding PECsw, max causing event in the simulations with micro-dams. These dates for with or without micro-dam installation were different in the R1 and R3 scenarios and identical in R2. In R1 and R3, the microdams were causing a delay, i.e. a later event delivered PECsw, max under the mitigated condition.

A corresponding PECsw,max for a situation without micro-dams ( $\mathrm{PEC}_{\mathrm{sw}}^{\mathrm{no}}$ mitigation $)$, that was required for the calculation of the mitigated PECsw,max $\left(\mathrm{PEC}_{\mathrm{sw}}^{\text {mitigation }}\right.$ ), using Eqs. (7) and (8) was derived with the TOXSWA metamodel [1], since it is not an output of TOXSWA.

\section{Results and discussion}

Table 2 lists the various effects of the application of micro-dams in potatoes and the distinct measures in maize cultivation as derived herein, both in measurable quantities and in subsequently derived runoff $\mathrm{CN}$. Table 3 shows the effects of a $\mathrm{CN}$ reduction on maximum predicted environmental concentrations (PECsw,max), for example FOCUS assessments for potatoes and three example substances.

\section{Observed effects of the management practices in the measurable quantities}

All mitigation measures lead to a decrease in runoff from the agricultural fields (Table 2$)-$ by $86 \%( \pm 7 \%)$ on average in the potato trials and by $51 \%( \pm 9 \%)$ in the maize trials, respectively. Similarly, the eroded sediment quantities were lowered-by $90 \%( \pm 6 \%)$ and $71 \%( \pm 6 \%)$, PPP loss was reduced (where applicable) by $88 \%( \pm 4 \%)$ in potato trials and by $46 \%( \pm 12 \%)$ in maize trials.

\section{Effects in derived curve numbers}

The runoff reductions are reflected in lower $\mathrm{CN}$, which were subsequently derived herein. Table 2 lists averages and percentiles; in Additional file 1, all single data are listed.

\section{Potatoes}

The evaluation of the field studies suggests that the potential application of micro-dams justifies a reduction of the average runoff $\mathrm{CN}$ for surface water exposure modelling. Here, the calculated reduction is on average 21 points from the mean $\mathrm{CN}$ of the untreated trials of 86. Keeping in mind, runoff being a non-linear function of $\mathrm{CN}$, an estimation for an analogous average reduction of the default value of 82 (e.g. during growing phases) in the FOCUS standard scenarios R1 and R3 can be made to be approximately 20 points, the 10th percentile being approximately 10 points (here: 12 points). For R2 with the default value of 78 , the values of the proposed reductions can be assumed to be identical.

In Olivier et al. [29], a rainfall-weighted average (each individual event is weighted by the corresponding amount of precipitation) of $\mathrm{CN}=83$ for the untreated setup was derived, being the result of 13 single events. Hence, this result was close to the standard FOCUS value of $\mathrm{CN}=82$. In 4 of the 17 events, the basin at the end of the untreated trial site was overflown. Consequently, the "true" extent of the mitigation could not be inferred in these cases, and the overall average constitutes an underestimation of the overall actual mitigation.

The two trials from Goffart et al. [21] consisted of three locations, each observed for 1 year. The absolute values of the calculated $\mathrm{CN}$ were much lower than those for the other studies (Additional file 1: Table S3). Due to the conceptual difference, the $\mathrm{CN}$ derived here were not included in the calculation of the averages.

In Aurbacher et al. [6], the reported overview table of 35 studies allowed for a calculation of one single average 
Table 2 Effects of micro-dams in potato cropping and distinct strategies in maize cultivation on runoff quantities, erosion, plant protection product (PPP) loads and curve numbers (CN; means), as means with standard deviations, 10th percentiles, and ranges; n.a.: not applicable

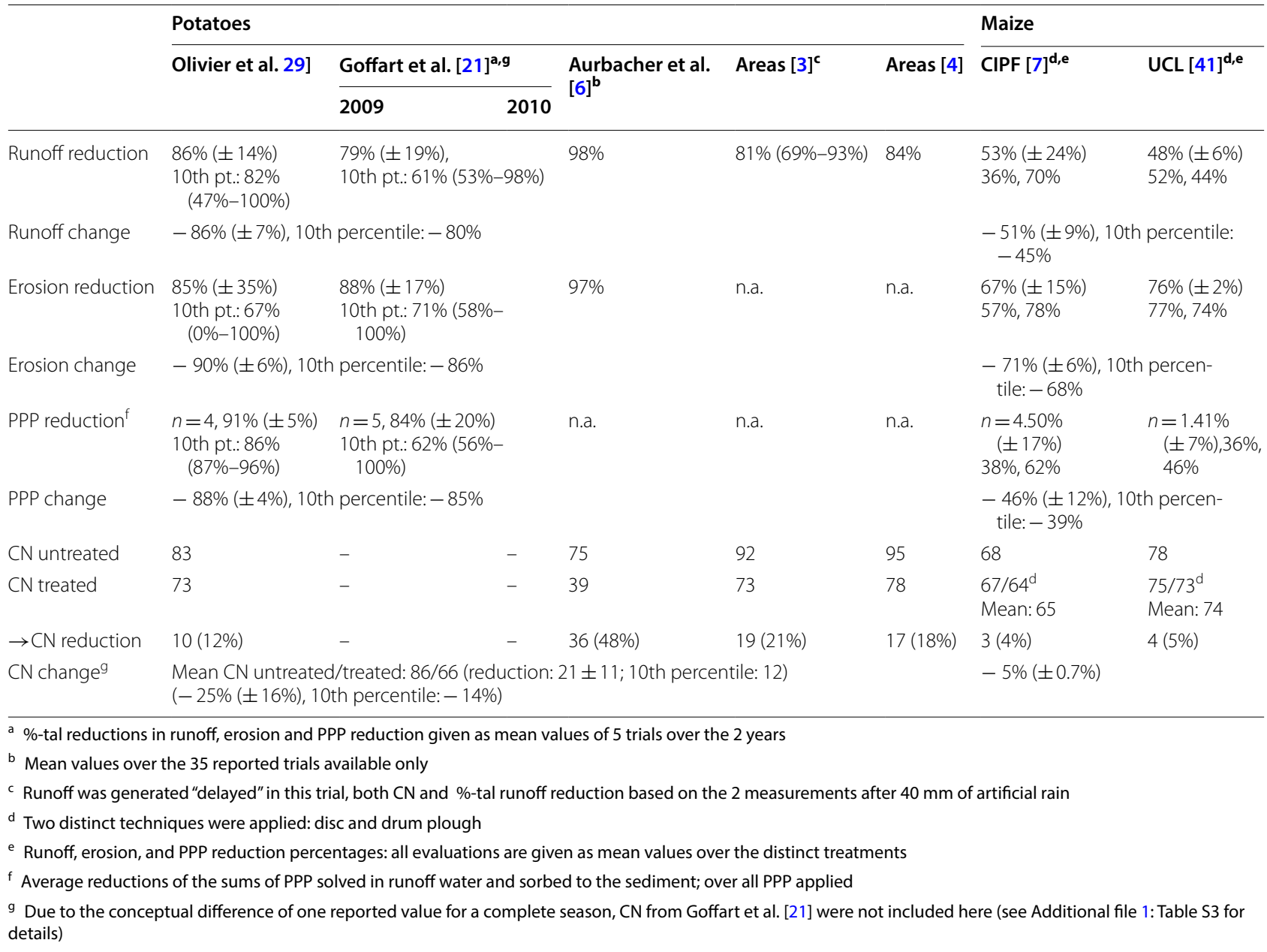

Table 3 Results from lowering the standard values of the runoff curve number (CN; intermediate antecedent moisture conditions, AMC II) by $10 \%$ : maximum predicted environmental concentrations for surface water (PECsw,max) ( $\mu$ g/l), calculated using FOCUS PRZM and TOXSWA and the standard scenarios for potatoes; The recalculated PECsw,max are based on runoff mass fluxes from FOCUS PRZM, considering a dilution from the upper catchment in the stream scenarios

\begin{tabular}{|c|c|c|c|c|c|c|c|c|c|}
\hline & \multicolumn{3}{|c|}{$\begin{array}{l}\text { Aclonifen (immobile) } \\
\left(1200 \mathrm{~g} \mathrm{ha}^{-1}\right)[10]\end{array}$} & \multicolumn{3}{|c|}{$\begin{array}{l}\text { Fluazinam (mod. mobile) } \\
\left(750 \mathrm{~g} \mathrm{ha}^{-1}\right)[11]\end{array}$} & \multicolumn{3}{|c|}{$\begin{array}{l}\text { Metribuzin [9] (highly mobile) } \\
\left(350 \mathrm{~g} \mathrm{ha}^{-1}\right)\end{array}$} \\
\hline & Regular CN & $\mathrm{CN}-10 \%$ & $\begin{array}{l}\text { PECsw,max } \\
\text { red. (\%) }\end{array}$ & Regular CN & $\mathrm{CN}-10 \%$ & $\begin{array}{l}\text { PECsw, max } \\
\text { red. }(\%)\end{array}$ & Regular CN & $\mathrm{CN}-10 \%$ & $\begin{array}{l}\text { PECsw,max } \\
\text { red. }(\%)\end{array}$ \\
\hline R1 stream ${ }^{a}$ & 1.43 & 0.35 & 76 & 0.85 & 0.20 & 76 & 0.61 & $6.7 \mathrm{E}-03$ & 99 \\
\hline R2 stream ${ }^{b}$ & 0.50 & 0.20 & 60 & 0.21 & 0.08 & 60 & 1.21 & 0.42 & 66 \\
\hline R3 stream ${ }^{c}$ & 1.83 & 0.50 & 73 & 1.32 & 0.33 & 75 & 21.1 & 0.22 & 99 \\
\hline
\end{tabular}

The substances under investigation are aclonifen, fluazinam and metribuzin, applied once \pm 14 days relative to emergence

a ACL and FLZ: event causing PECsw,max occurs on May 20th and on May 30th 1984 without and with the application of micro-dams, respectively; MTB: on May 7th and on May 20th 1984, respectively

b All three substances: both with and without the application of micro-dams, PECsw,max causing event occurs on March 11 th 1977

c All three substances: event causing PECsw,max occurs on April 2nd and on April 20th 1980 without and with the application of micro-dams 
value of reduction. A CN reduction of 36 points (from 75 to 39 ) was derived from the annually reported data.

After the application of artificial rain of $40 \mathrm{~mm}$ in the trial of Areas [3], an average reduction of 19 points $(\mathrm{CN}$ 92 to 73 ) was observed over the two setups with dry and humid initial conditions, respectively. The $\mathrm{CN}$ in the later study of Areas [4] was reduced to a very similar extent: after $30 \mathrm{~mm}$ of artificial rain, the $\mathrm{CN}$ was decreased by 17 points (CN 95 to 78$)$.

\section{Maize}

The outcome of the maize trials investigating the applications of disc plough or drum plough can be summarized as a reduction of the average $\mathrm{CN}$ of 73 to 70 points. This also implies a reduction of 3 points in the FOCUS standard scenarios R1-R4.

For the trial of CIPF [7], conducted over a complete season and averaged over two repetitions of the treatments on different slopes, an overall precipitationweighted reduction of 3 points (from 68 to 65) was derived (Additional file 1: Table S14). The differences between the two applied techniques and slopes were considerably small.

In UCL [41], the average over the two reported events was $\mathrm{CN}=78$ for the untreated setup and $\mathrm{CN}=74$ for the setups after treatment with disc or drum plough.

\section{Example calculations of predicted environmental concentrations}

In the numerical simulations for risk assessment using FOCUS PRZM, edge-of-field concentrations in runoff are not necessarily reduced when lowering the $\mathrm{CN}$, since both water and mass fluxes are reduced. However, PECs in the receiving water body will be reduced by dilution due to the contribution of unmodified streamflow from the upstream catchment.

A considerable reduction of the concentrations reaching the surface water body is achieved when the installation of micro-dams causes a time-delay of the mass entries by eliminating events closer to application and, consequently, more time for leaching and degradation becomes available.

To consider the effects of micro-dam application adequately, the fact that only the treated agricultural field is assumed to be equipped with micro-dams can be taken into account. Then other areas of the upper-stream catchment contribute to a dilution with the inflow of the not-mitigated amount of water in the surface water body.

Table 3 lists the PECsw,max after globally decreasing the value for the $\mathrm{CN}$ in the input files for the standard potato scenario by $10 \%$ (and otherwise conducting a regular assessment) and additionally recalculating the
PECsw,max taking the effect of dilution from the upperstream catchment into account. Table S16 in Additional file 1 shows the detailed results after the recalculation, i.e. PRZM runoff fluxes with and without the application of micro-dams, the corresponding reduction factors $f$ and PECsw,max.

In the stream scenarios R1 and R3, the specific runoff events that lead to the PECsw,max are later ones due to the application of micro-dams (R1: 10 days for ACL and FLZ, 13 days for MTB; R3 for all three: 18 days). There, the PECsw,max-decreasing effect of globally lowering the $\mathrm{CN}$ is higher than for $\mathrm{R} 2$.

Due to the interplay of runoff and erosion driven by runoff, a general statement whether highly mobile (less sorptive) or less mobile (higher sorptive) substances are more affected by a reduction of $\mathrm{CN}$ cannot be given.

\section{Consequences for risk assessment and risk management}

The trials under investigation in this study show a great extent of heterogeneity due to the differences in the execution of the field trials (Table 1) and the type of reporting (i.e. either reported for single events or as multiple events over a complete season). Nevertheless, the averaged results are considered suitable to quantify the effects of micro-dams in potato and maize cultivation.

In risk assessment in case micro-dams or similar techniques are applied, either a conservative default mitigation effectiveness can be used or a higher-tier assessment can be conducted, as, e.g. deriving PRZM CN for specific measures as presented here for micro-dams. The SETAC MAgPIE workshop [35] proposed to generally lower the mean $\mathrm{CN}$ by 3 points (or alternatively reduce the surface water concentration by $50 \%$ ) to account for micro-dams or other in-field bunds. The findings in this report for potato cultivation suggest reductions of $\mathrm{CN}$ far beyond the recommendation of the MAgPIE workshop of only a 3-point reduction, which was however based on one study only, which is not generally accessible.

Generally, the choice of $\mathrm{CN}$ has considerable consequences: for small-to-moderate rain events the predicted amount of runoff is proven to be highly sensitive to wrong assumptions of $\mathrm{CN}$ [23]. For example, an overestimation of $\mathrm{CN}$ by $10 \%$, for a precipitation of $5 \mathrm{~mm}$ and $\mathrm{CN}=80$ (which is in the range of the standard values for potatoes and maize) leads to an overestimation of runoff by $100 \%$.

\section{General considerations}

For the effective prevention of surface runoff and erosion it is advised to minimize runoff generation on-site (via increasing infiltration) and to maximize runoff retention off-site (e.g. via buffer strips). On-site runoff prevention should always be the preferred option because it reduces 
the risk of high runoff flow velocities and the generation of rill-flow which makes off-site runoff retention much more difficult and expensive. It has been reported, that an increase in the quantity of runoff leads to an exponential increase in pesticide transfer from the field, whereas subsequent measures, i.e. buffer strips lead to a linear decrease in pesticide transfer when capturing runoff and erosion [35].

Besides the reduction of runoff, the practice to create micro-dams is reported to lead to an improved water and nutrient supply in the agricultural field and consequently to a yield increase $[22,34,37]$. Hence, the application of these mitigation practices shows many benefits and can adequately be included in the risk assessment, if applied by the farmer.

\section{Conclusion}

Following the application of micro-dams, the runoff water volume in the field trials was substantially reduced, on average by $86 \%$ for potatoes and $51 \%$ for maize. The reduction percentages for the plant protection products were very similar to the reduction of the water runoff, on average by $88 \%$ for potatoes and $46 \%$ for maize. Even more reduced was the eroded soil mass, on average by $90 \%$ for potatoes and $71 \%$ for maize.

The reductions of the runoff water volume were translated into reduction of the runoff curve number $(\mathrm{CN})$. In the regulatory exposure assessment context, generally realistic worst-case assumptions are made for distributed driving variables such as $\mathrm{CN}$ to safeguard a sufficiently conservative assessment. Based on the findings in this report, we propose a 10-point reduction of the $\mathrm{CN}$ for the FOCUS R1-R3 potato scenarios which conservatively represents the $10^{\text {th }}$ percentile of measured reductions and a 3-point reduction (mean from two studies) of the $\mathrm{CN}$ for maize to account for the mitigation of runoff and erosion losses from treated fields by micro-dams.

As conclusion from this study, we recommend the adoption of $\mathrm{CN}$ reductions due to micro-dams in potatoes and other comparable measures in maize into the regulatory exposure assessment. We propose an absolute reduction of the $\mathrm{CN}$ in risk assessment in accordance with the findings in this study.

In risk assessment, the installation of micro-dams can be considered in a higher-tier calculation which will lead to reduced predicted environmental concentrations.

\section{Supplementary information}

Supplementary information accompanies this paper at https://doi. org/10.1186/s12302-020-00362-1.

Additional file 1. Additional tables.

\section{Abbreviations}

AMC: Antecedent moisture condition; CN: Curve number; EFSA: European Food Safety Agency; FOCUS: FOrum for Co-ordination of pesticide fate models and their Use; MAgPIE: Mitigating the risks of plant protection products in the environment; PEC: Predicted environmental concentration; PECsw: Predicted environmental concentration for the surface water compartment; PPP: Plant protection product; PRZM: Pesticide root zone model; SETAC: Society of Environmental Toxicology and Chemistry; TOXSWA: TOXic substances in Surface Waters; USDA: United States Department of Agriculture.

\section{Acknowledgements}

The authors thank the Centre Wallon de Recherches Agronomiques (CRA-W) and Ulg-Gembloux Agro-Bio Tech for collaboration in the potato trials and Centre Indépendant de Promotion Fourragère (CIPF) in the maize trials.

\section{Authors' contributions}

SS analyzed and interpreted the field data (newly designed and from literature), calculated the curve numbers and predicted environmental concentrations. RS guided the evaluation and was major contributor to the manuscript. DB was responsible for the conduction and evaluation of the field trials by the contractor companies and provided very valuable practical expertise. $\mathrm{KH}$ provided the strategy to derive the predicted environmental concentrations according to the European risk assessment framework and was a major contributor to the manuscript. All authors read and approved the final manuscript.

\section{Funding}

The work on this manuscript and the evaluations shown therein were funded by Bayer AG. The trials of Olivier et al. [29] and CIPF [7] were conducted in behalf of the Bayer AG.

\section{Availability of data and material}

All data generated or analyzed during this study are included in this published article, i.e. in additional file.

\section{Ethics approval and consent to participate}

Not applicable.

\section{Consent for publication}

Not applicable.

\section{Competing interests}

The authors declare that they have no competing interests.

\section{Author details}

${ }^{1}$ knoell Germany GmbH, Konrad-Zuse-Ring 25, 68163 Mannheim, Germany.

${ }^{2}$ Bayer AG Division Crop Science, Alfred-Nobel-Str. 50, 40789 Monheim, Germany. ${ }^{3}$ Bayer AG Division Crop Science, Jan-Emiel Mommaertslaan 14, 1831 Machelen, Belgium.

Received: 18 February 2020 Accepted: 25 May 2020

Published online: 01 June 2020

\section{References}

1. Adriaanse PI, Van Leerdam RC, Boesten JJTI (2017) The effect of the runoff size on the pesticide concentration in runoff water and in FOCUS streams simulated by PRZM and TOXSWA. Sci Total Environ 584-585:268-281

2. Areas (2012) Association Régionale pour l'Etude et l'Amélioration des Sols: Expérimentations sur les pratiques culturales 2001-2010: synthèse des résultats de ruissellement et d'érosion. http://www.areasasso.fr/ images/resultats\%20essais\%20simul/brochure_10ans_essais_PC_ruiss ellement.pdf. Accessed 15 Nov 2017

3. Areas (2005) Réduction du ruissellement de printemps sur pomme de terre-effet des micro-barrages. http://www.areas-asso.fr/images/resul tats\%20essais\%20simul/AREAS-2005-11.pdf. Accessed 07 Feb 2020

4. Areas (2007) Pomme de terre. Limiter la formation du ruissellement en sol limoneux. Simulation de pluie (30 mm) juin 2007 Saint-Jouin-Bruneval. http://www.areas-asso.fr/wp-content/uploads/2016/11/8-pommes-deterre.pdf. Accessed 07 Feb 2020 
5. Beltman WHJ, Horst MMS ter, Adriaanse PI, Jong A de, Deneer JW (2014) FOCUS TOXSWA manual 4.4.2: Users Guide version 4. WOt-technical report 14. Wettelijke Onderzoekstaken Natuur \& Milieu, Wageningen

6. Aurbacher J, Krimly T, Billen N (2010) Querdammhäufler verringert Bodenund Wasserverluste-ein Gerät zur Erosionsverringerung im Kartoffelbau. Landwirtschaftliches Wochenblatt/Hessenbauer/Ausgabe Süd

7. CIPF (2013) Erosiebestrijding in maïs. Internal communication Bayer CropScience, cooperation with Centre indépendant de promotion fourragère (Louvain-la-neuve, Belgium) 04.03.2015. Personal communication, not published

8. ECPA and Tessella Support Services plc. (2008) Surface Water Assessment eNabler (SWAN) v 1.1.4

9. EFSA (2006) Conclusion on the peer review of metribuzin. EFSA Sci Rep 88:1-74

10. EFSA (2008) Conclusion on the peer review of aclonifen. EFSA Sci Rep 149:1-80

11. EFSA (2008) Conclusion regarding the peer review of the pesticide risk assessment of the active substance fluazinam. EFSA Sci Rep 137:1-82

12. EFSA (2011) Conclusion on the peer review of the pesticide risk assessment of the active substance terbuthylazine. EFSA J 9(1):1969

13. EFSA (2013) Conclusion on the peer review of the pesticide risk assessment of the active substance tembotrione. EFSA J 11(3):3131

14. EFSA (2018) Scientific report of EFSA on the "repair action" of the FOCUS surface water scenarios. EFSA J (under development). https://www.efsa. europa.eu/sites/default/files/consultation/consultation/Draft_EFSA_scien tific_report_FOCUS.pdf. Accessed 29 Apr 2020

15. Elhakeem M, Papanicolaou T (2009) Estimation of the runoff curve number via direct rainfall simulator measurements in the State of lowa, USA. Water Resour Manag 23:2455-2473

16. EPA (2016) Pesticide in water calculator user manual for versions 1.50 and 1.5. Dirk F. Young, U.S. Environmental Protection Agency, Washington, DC

17. ESA (1973) Endangered Species Act of 1973. Codified 16 U.S.C. § 1531 et sea

18. FOCUS (2001) FOCUS surface water scenarios in the EU evaluation process under 91/414/EEC. Report of the FOCUS working group on surface water scenarios, EC Document Reference SANCO/4802/2001-rev.2

19. FOCUS (2015) Generic guidance for FOCUS surface water Scenarios, version 1.4, May 2015. EU Document

20. EFSA (2016) Conclusion on the peer review of the pesticide risk assessment of the active substance linuron. EFSA J 14(7):4518

21. Goffart JP, Poulet V, Olivier C (2013) Study of the effects of tied ridges on water runoff and its consequences for potato crop. Potato Agrophysiol 15:55-61

22. Harris BL, Krishna JH (1989) Furrow diking to conserve moisture. J Soil Water Conserv 44(4):271-273

23. Hawkins R (1975) The importance of accurate curve numbers in the estimation of storm runoff. Water Resour Bull 11(5):887-891

24. Hawkins R (1993) Asymptotic determination of runoff curve numbers from data. J Irrig Drain E 119(2):334-345

25. ter Horst MMS, Adriaanse PI, Boesten JJTI (2009) Interpretation of the mitigation of runoff in the FOCUS surface water scenarios as described in the FOCUS L\&M report. Alterra, Alterra-Report, Wageningen, p 1794

26. Jones OR, Baumhardt RL (2003) Furrow dikes. In: Trimble S (ed) Encyclopedia of water science. CRC Press, Boca Raton

27. Mockus V (1949) Estimation of total (and peak rates of) surface runoff for individual storms. Exhibit A of Appendix B, interim survey report, Grand (Neosho) River Watershed, USDA Soil Conservation Service

28. Oliveira PTS, Nearing MA, Hawkins RH, Stone JJ, Rodrigues DBB, Panachuki E, Wendland E (2016) Curve number estimation from Brazilian Cerrado rainfall and runoff data. J Soil Water Conserv 71 (5):420-429
29. Olivier C, Goffart JP, Baets D, Xanthoulis D, Fonder N, Lognay G, Barthélemy JP, Lebrun P (2014) Use of micro-dams in potato furrows to reduce erosion and runoff and minimise surface water contamination through pesticides. Comm Appl Biol Sci 79(2):1-10

30. PPDB (2016a): Pesticide Properties DataBase. University of Hertfordshire: https://sitem.herts.ac.uk/aeru/ppdb/en/Reports/331.htm. Accessed 04 Dec 2017

31. PPDB (2016b): Pesticide Properties DataBase. University of Hertfordshire: https://sitem.herts.ac.uk/aeru/ppdb/en/Reports/424.htm. Accessed 04 Dec 2017

32. PPDB (2017): Pesticide Properties DataBase. Data interpretation; University of Hertfordshire: http://sitem.herts.ac.uk/aeru/ppdb/en/docs/5_1.pdf. Accessed 04 Dec 2017

33. Reichenberger S, Bach M, Skitschak A, Frede HG (2007) Mitigation strategies to reduce pesticide inputs into ground- and surface water and their effectiveness; A review. Sci Total Environ 384:1-35

34. Salem HM, Valero C, Muñoz MÁ, Gil-Rodríguez M (2015) Effect of integrated reservoir tillage for in situ rainwater harvesting and other tillage practices on soil physical properties. Soil Till Res 151:50-60

35. SETAC (2017) Alix A, Brown C, Capri E, Goerlitz G, Golla B, Knauer K, Laabs V, Mackay N, Marchis A, Alonso Prados E, Reinert W, Streloke M, Poulsen V (eds.). MAgPIE - mitigating the risks of plant protection products in the environment. From the two-part SETAC Workshop Mitigating the Risk of Plant Production Products in the Environment. https://www.setac.org/ store/ViewProduct.aspx?id=9006489. Accessed 09 Sept 2017

36. Suárez LA (2006) PRZM-3, A model for predicting pesticide and nitrogen fate in the crop root and unsaturated soil zones: user's manual for release 3.12.2.

37. Sui Y, Ou Y, Yan B, Xu X, Rousseau AN, Zhang Y (2016) Assessment of micro-basin tillage as a soil and water conservation practice in the black soil region of Northeast China. PLoS ONE 11(3):e0152313

38. Tang R, Zhu B, Katou H (2012) A review of rapid transport of pesticides from sloping farmland to surface waters: processes and mitigation strategies. J Environ Sci 24(3):351-361

39. Truman C, Nuti R (2010) Furrow diking in conservation tillage. Agric Water Manage 97:835-840

40. UBA (2018) Federal German Environmental Protection Agency—Umweltbundesamt. https://www.umweltbundesamt.de/en/topics/soil-agricultur e/land-a-precious-resource/erosion\#textpart-9. Accessed 11 Jan 2018

41. UCL (2012) Lutte contre le ruissselement et l'érosion en culture de maïs sur terres en pente. Cooperation of UCL, LSM, CIPF, SPW and DGO3. Personal communication, not published

42. FIFRA (1980) Federal Insecticide, Fungicide, and Rodenticide Act. Codified 7 U.S.C. § 136 et sea

43. USDA (2004) United States Department of Agriculture, Natural Resources Conservation Service; Estimation of direct runoff from storm rainfall. Part 630 Hydrology — National engineering handbook, chapter 10

44. Young DF, Fry FF (2014) PRZM5. A model for predicting pesticide in runoff, erosion, and leachate: user manual. USEPA/OPP 734F14002. Office of Pesticide Programs U.S. Environmental Protection Agency

\section{Publisher's Note}

Springer Nature remains neutral with regard to jurisdictional claims in published maps and institutional affiliations. 